УДК 338.5

DOI: 10.14451/1.196.60

\title{
АЛГОРИТМЫ ИЗМЕНЕНИЙ БИЗНЕС-МОДЕЛИ ПРЕДПРИНИМАТЕЛЬСКОЙ ДЕЯТЕЛЬНОСТИ В УСЛОВИЯХ КРИЗИСНЫХ ЯВЛЕНИЙ
}

\author{
(c) 2021 Волкодавова Елена Викторовна \\ доктор экономических наук, профессор \\ Самарский государственный экономический университет, Россия, Самара \\ E-mail:vev.sseu@gmail.com \\ (C) 2021 Жабин Александр Петрович \\ доктор экономических наук, профессор \\ Самарский государственный экономический университет, Россия, Самара \\ E-mail:apzhabin@yandex.ru
}

Изменение бизнес-модели предпринимательских структур, функционирующих в условиях кризисной экономики остается одним из актуальных направлений современных исследований теоретиков и практиков многих стран. Проанализированы и оценены направления изменений, предпринимаемые в кризисных ситуациях менеджментом российских бизнес-структур. В статье представлены разработанные авторами алгоритмы изменений бизнес-модели, направленные на восстановление и развитие предприятий малого и среднего бизнеса, функционирующих в условиях кризисных явлений.

Ключевые слова: бизнес-модель, кризисные явления, предпринимательские структуры, адаптация к условиям рынка

\section{Введение.}

С марта месяца 2020 года практически все российские малые и средние предприятия испытали на себе в той или иной степени экстремальные условия ведения бизнеса, вызванные пандемией COVID 19. Большинство российских предприятий малого и среднего бизнеса занята в области торговли и услуг, поэтому введение карантинных условий внутри страны и закрытие таможенных границ особенно остро повлияли на приостановку или прекращение их деятельности. Первым пандемия затронула туристский бизнес, а затем сквозной цепочкой потерей рынка и неплатежей были охвачены и все остальные российские предприятия малого и среднего бизнеса.

Правительство РФ сразу же приняло действенные меры по смягчению «коронавирусного удара» на малый и средний бизнес и по сей день прилагает все усилия для восстановления его устойчивой деятельности. На сайте «Государственная Дума Федерального Собрания Российской Федерации» изложен ряд действующих мер поддержки предпринимателей [1]. Среди этих мер: субсидирование, льготное кредитование, отсрочка уплаты налогов и других платежей и многие другие.

11 мая 2020 г. на совещании о санитарно- эпидемиологической обстановке, которое проводил Президент РФ В.Путин, были представлены новые меры поддержки предприятий малого и среднего бизнеса, среди которых: с 1 июня 2020 г. действует специальная кредитная программа поддержки занятости, которая распространяется на все предприятия в пострадавших отраслях; введено полное списание налогов и страховых взносов за второй квартал 2020 года (предоставлена отсрочка по налогам и страховым платежам на шесть месяцев с возможностью гасить их затем плавно, в течение года, полностью списать, за исключением НДС) [2]. Но, учитывая масштабы кризиса и широту его охвата сегмента субъектов малого и среднего бизнеса, этот пакет мер оказался для большинства российских предприятий либо недостаточно действенными, либо труднодоступными из-за бюрократической цепочки их оформления. В начале 2021 года многие из мер продлены, так, например, проверки приостановлены до 31 декабря 2021 года, но по некоторым видам деятельности малых и средних предприятий остаются локальные региональные ограничения это относится, например, к предприятиям общепита.

В настоящее время любой российский предприниматель может изучить обширный ряд мер 
поддержки предпринимателей, актуальных в условиях пандемии корон вируса COVID - 19, и другую полезную информацию, представленные на сайте СТОПКОРОНОВИРУС.РФ [3]. Практически все эти меры направлены на восстановление и поддержание прежних экономических и конкурентных позиций малых и средних предприятий. На какое-то время применение этих мер обеспечивает экономическую безопасность деятельности МСП. Но они очень важны и необходимы не только для тех МСП, которые хотят вернуть или сохранить прежние объемы и направления деятельности. Они являются также исходным этапом для создания базы, основы дальнейшего развития МСП. В этой связи перед менеджерами и собственниками малых и средних предприятий особенно остро встает вопрос организации управления бизнесом в неопределенной и нестабильной экономической среде, который, по нашему мнению, в первую очередь, касается корректировки или радикального изменения существующей бизнес-модели.

Именно это обеспечит малым и средним предприятиям возможность устойчивого развития бизнеса и экономической безопасности функционирования в сегментах занимаемых рынков.

\section{Теория.}

Изменение бизнес-модели в кризисных условиях ведения бизнеса, прежде всего, зависит от намерений предпринимателей:

- выжить и вернуть бизнес на исходную позицию, сохранив действующую бизнес-модель;

- развиваться устойчиво, с перспективой развития бизнеса, усовершенствовав действующую бизнес-модель с учетом параметров изменения бизнес-среды;

- диверсифицировать деятельность, выявить и обосновать новые ее направления на основе радикального изменения бизнес-модели.

Кроме этого, предприниматели должны определиться по поводу применяемых методов, инструментария и целевых установок деятельности в рамках новой бизнес-модели в условиях неопределенной экономической среды.

Как показывает практика, процесс изменения бизнес-модели, как правило, инициируется российским бизнесом в последнюю очередь. На первом месте стоят задачи восстановления докризисных параметров.

О. Кайтялиди в своей статье «Как трансформировать бизнес-модели: алгоритмы, которые работают» [4] приводит результаты исследования, компании Strategy Partners, согласно которым 91\% российских компаний до сих пор применяют устаревающую бизнес-модель и не торопятся ее изменять, что приводит к печальным последствиям потери рыночной ниши, объемов продаж, уровня прибыли. В то время как бизнес-модель любого субъекта предпринимательства, интегрированного в систему современных рыночных отношений, отражающая механизм цепочки создания ценности, должна быть адаптированной к конкретному состоянию его рыночной ниши.

Самым правильным выходом из кризиса считаем применение стратегии инновационного прорыва, о которой указывает в своих трудах «Черный лебедь. Под знаком неопределенности» [5] и «Антихрупкость. Как извлечь выгоду из хаоса» Н.Талеб [6]. Действительно, возврат к прежнему состоянию - это шаг назад, в прошлое деятельности компании [7]. Стратегия восстановления прежних позиций какое-то время поможет предприятию «удержаться на плаву». Но в кризисных условиях среды спрос и предложение могут кардинально меняться. В этом случае встает вопрос о необходимости идти дальше, а это - прямой путь к развитию, к внедрению инноваций. Идти дальше - это вводить то новое, что позволит малым и средним предприятиям создать или увеличить конкурентные преимущества в занятых сегментах рынка по товару или услуге.

Инновации можно применять в различных сферах деятельности МСП. Так, например, В.Л.Тамбовцев в своей статье «Стратегическая теория фирмы: состояние и возможное развитие» указывает на шесть подходов, развиваемых в настоящее время в теории фирмы: транзакционный, ресурсный, когнитивный, процессный, предпринимательский и подход, основанный на учете динамических способностей фирмы [8, с. 6]. Согласно этому подходу инновационные преобразования могут быть направлены на совершенствование техники заключения контрактов, оптимального использования имеющихся ресурсов, создания информационных баз данных, применяемых и внедряемых бизнес-процессов, стратегиях и тактиках адаптации деятельности и т.д.

\section{Данные и методы.}

В качестве основных, авторы применили: методы комплексного и системного анализа, 
которые позволили: выявить ключевые элементы и алгоритмы изменения бизнес модели предпринимательских структур в условиях кризисных ситуаций; концепцию рационального поведения рыночных субъектов, позволяющую обосновать бизнес-стратегии российских предпринимателей в условиях пандемии COVID - 19.

Экспериментальная база исследования предпринимательская деятельность российских малых и средних предприятий.

Результат. В условиях кризиса в экономике объективной необходимостью становится поиск не только путей обеспечения устойчивости работы предприятий, но также и способов достижения безопасного и эффективного развития бизнеса. Как показывает практика [4], в кризисной ситуации бизнес прежде всего вносит инновационные изменения в улучшение продукта, систему управления, обучение персонала, модернизацию производства, но самыми продуктивными оказываются изменения действующей бизнес-модели. Авторы полностью согласны с этим положением.

Так как же нужно корректировать бизнесмодель, чтобы она отвечала современным требованиям ведения бизнеса? Все зависит от вида предпринимательской деятельности, которая может быть направлена на создание продукта, услуги, объекта интеллектуальной собственности; сложности и эффективности действующей бизнес-модели; тех ресурсов, которыми располагает предприниматель, включая финансовые и человеческие. Авторы предлагают алгоритм реструктуризации бизнес-модели, ориентированной на продукт, в случае если изменение бизнес-модели в кризисной ситуации направлены не только на сохранение, но и дальнейшее развитие рыночной ниши при условии существующих ресурсных и финансовых возможностях внедрения изменений.

Самым ответственным моментом является выявление изменений в блоках существую-

Таблица 1. Факторы, определяющие направление и возможность преобразования бизнес-модели, ориентированной на продукт

\begin{tabular}{|c|c|}
\hline Фактор & Направления изменений \\
\hline 1. Сложность существующей модели бизнеса & $\begin{array}{l}\text { 1.1. Выявление блоков, нуждающихся в изменении } \\
\text { 1.2. Оценка направлений необходимых изменений } \\
\text { 1.3. Определение приоритетных изменений }\end{array}$ \\
\hline $\begin{array}{l}\text { 2. Совокупность бизнес-процессов производства } \\
\text { каждого продукта, нуждающегося в инновационном } \\
\text { изменении: } \\
\text { - основных; } \\
\text { - вспомогательных; } \\
\text { - обслуживающих. }\end{array}$ & $\begin{array}{l}\text { 2.1. Ревизия бизнес-процессов на соответствие при- } \\
\text { меняемой инновационной технологии. } \\
2.2 \text { Определение бизнес-процессов: } \\
\text { - новых, намечаемых к внедрению; } \\
\text { - существующих, эффективных; } \\
\text { - неэффективных, которые необходимо удалить из } \\
\text { действующей технологической цепочки }\end{array}$ \\
\hline $\begin{array}{l}\text { 3. Технологическая применяемость существующе- } \\
\text { го оборудования к производству инновационного } \\
\text { продукта }\end{array}$ & $\begin{array}{l}\text { 3.1. Анализ возможности выполнения новых техно- } \\
\text { логий на существующем оборудовании } \\
\text { 3.2. Разработка спецификации оборудования, необхо- } \\
\text { димого для выполнения технологических процессов } \\
\text { новой бизнес-модели }\end{array}$ \\
\hline $\begin{array}{l}\text { 4. Финансовое положение субъекта предпринима- } \\
\text { тельства }\end{array}$ & $\begin{array}{l}\text { Анализ возможности финансирования изменений } \\
\text { бизнес-модели: } \\
\text { - за счет собственных средств; } \\
\text { - за счет привлеченных средств. }\end{array}$ \\
\hline $\begin{array}{l}\text { 5. Уровень компетентности персонала к работе с } \\
\text { новыми технологиями }\end{array}$ & $\begin{array}{l}\text { 5.1. Анализ компетенций персонала для выполнения } \\
\text { новых бизнес-процессов } \\
\text { 5.2. Оценка возможности обучения, подготовки и } \\
\text { переподготовки персонала }\end{array}$ \\
\hline $\begin{array}{l}\text { 6. Необходимость изменений оргструктуры и меж- } \\
\text { функционального взаимодействия специалистов } \\
\text { отделов }\end{array}$ & $\begin{array}{l}\text { 6.1. Анализ организационной структуры и структуры } \\
\text { управления, документооборота, связанного с орга- } \\
\text { низацией процесса производства и управления в } \\
\text { рамках изменения бизнес-модели }\end{array}$ \\
\hline $\begin{array}{l}\text { 7. Уровень цифровизации всех бизнес-процессов } \\
\text { предприятия }\end{array}$ & $\begin{array}{l}\text { 7.1. Анализ уровня цифровизации взаимодействия } \\
\text { всех подразделений и структур предприятия. } \\
\text { 7.2. Оценка уровня цифровизации бизнес-процессов } \\
\text { 7.3. Оценка потребности в оборудовании, обеспечи- } \\
\text { вающем информатизацию бизнес-взаимодействия } \\
\text { структур предприятия и бизнес-процессы. }\end{array}$ \\
\hline
\end{tabular}


щей бизнес-модели. Сложность действующей бизнес-модели определяется стратегическими направлениями деятельности субъекта предпринимательства, применяемыми технологиями изготовления продукта или услуги, организацией производства и управления. Фактически блоки бизнес-модели описывают способ получения прибыли, адаптированный к потребностям клиента. Следовательно, изменение модели будет определять, как в дальнейшем она будет генерировать ценность, и что для этого необходимо предпринять.

В нашем конкретном случае рыночные изменения могут вызвать корректировку потребительской ценности продукта, изменение технологии ее создания и системы управления производством и сбытом. В результате новая ценность продукта позволит либо оставить за предприятием рыночный сегмент, либо его расширить, что соответственно сохранит финансовые показатели деятельности, либо их улучшит.

Интеграционное взаимодействие блоков бизнес-модели должно осуществляться на основе изменения материально-маршрутных спецификаций в рамках технологических процессов и управленческих функций, на основе оперативного учета совокупного воздействия факторов внешней среды и внутреннего состояния субъекта предпринимательства.

В результате могут быть существенно скорректированы базовые блоки бизнес-модели, такие, как:

- ценность продукта для потребителя;

- технология создания ценности;

- технология управления созданием ценности (оргструктура, изменения межфункционального взаимодействия в рамках существующей производственной площадки);

- компетенции персонала;

- формирование денежного потока.

Как было сказано выше, создание новой ценности продукта для потребителя должно быть основано на инновационном изменении его характеристик или технологии его изготовления. Только в этом случае будет сформирован портфель, обеспечивающий фирме реальный рост бизнеса. Но, как показывает практика, не все предприниматели могут встать на путь инновационного развития.

Необходимо также отметить, что внесение изменений в указанные блоки бизнес-модели должно быть комплексным и системным, осуществляться на основе цифровизации информационных потоков. Комплексность подразумевает учет влияния изменений не только отдельных блоков бизнес-модели, но и всех остальных. Системность реализуется через эффективное управленческое воздействие, осуществляющее планирование, организацию и координацию бизнес-процессов модели во взаимосвязи и взаимозависимости всех блоков бизнес-модели.

Инновации внедряются за счет инвестиционных ресурсов, которыми обладают или которые могут привлечь предприниматели. Но доля действительно инновационных преобразований, как показывает статистика предпринимательской деятельности мала. Так, в сборнике Федеральной службы государственной статистики «Малое и среднее предпринимательство в России» за 2019 год [9] представлены показатели «Распределение малых предприятий по оценке целей инвестирования в основной капитал», приводятся следующие данные за 2018 год (см. табл. 2).

Таблица 2. Распределение малых предприятий по оценке целей инвестирования в основной капитал

\begin{tabular}{|l|c|}
\hline \multicolumn{1}{|c|}{ Цели инвестирования } & Доля инвестированного капитала,\% \\
\hline 1. Замена изношенной техники и оборудования & 20 \\
\hline $\begin{array}{l}\text { 2. Автоматизация и механизация существующего производственно- } \\
\text { го процесса }\end{array}$ & 16 \\
\hline $\begin{array}{l}\text { 3. Увеличение производственных мощностей с неизменной но- } \\
\text { менклатурой продукци }\end{array}$ & 14 \\
\hline $\begin{array}{l}\text { 4. Увеличение производственных мощностей с расширением но- } \\
\text { менклатуры продукции }\end{array}$ & 10 \\
\hline 5. Снижение себестоимости продукции & 10 \\
\hline 6. Внедрение новых производственных технологий & 9 \\
\hline 7. Создание новых рабочих мест & 7 \\
\hline 8. Экономия энергоресурсов & \\
\hline
\end{tabular}

Составлено авторами по данным Федеральной службы государственной статистики 
Согласно данным таблицы, в 2018 году $72 \%$ инвестиций в основной капитал было потрачено малыми предприятиями на традиционную деятельность и только 33\% (пункты 4,6,7) на инновационные изменения.

Данные, приведенные в таблице 2 подтверждают сказанное выше о том, что малый бизнес не стремиться к кардинальным инновационным изменениям. Но приведенные ниже, данные позволяют утверждать, что это не всегда происходит по субъективным причинам.

Факторы, сдерживающие инвестиционную деятельность предприятий малого бизнеса в 2017 и 2018 г.г, приведенные в [9, с.42], представлены в таблице 3.

Повышение потребительской ценности продукта или услуги напрямую связано с внедрением инновационных технологий, для чего необходимы существенный объемы привлечения денежных средств. А, судя по данным, приведенным в пунктах 3,5,6 и 7 таблицы 3, привлечение финансовых средств даже в относительно стабильные для малого и среднего бизнеса 2017 и 2018 годы было затруднено. Тем не менее, менеджмент малых и средних предприятий, используя возможности, предоставленные господдержкой предпринимательства, старается решить насущные проблемы, связанные с функционированием своих предприятий в кризисной среде.
В случаях, когда рыночная ниша утеряна или существенно снижена и отсутствуют ресурсные возможности для изменений бизнес-модели, предпринимателям следует обратиться к опыту лучших практик, изложенных, например, в научных трудах $[10,11]$.

\section{Выводы:}

В условиях кризисных явлений большинство российских предпринимателей используют модель поведения, направленную на восстановление прежних, докризисных объемов производства, с помощью традиционных организационных, управленческих и кадровых изменений в рамках существующей бизнесмодели. Но не только и не столько эти изменения, а кардинальные изменения структуры самой бизнес-модели позволят создать новую ценность, обеспечивающую дальнейшую устойчивость бизнеса. Именно этому способствуют алгоритмы изменения бизнес-модели, предложенные авторами статьи. При выполнении всех необходимых и обоснованных с позиции современных условий хозяйствования и потребностей клиентов изменений, реконструированная бизнес-модель будет обладать свойствами адаптивности и обеспечивать конкурентоустойчивость деятельности субъекта предпринимательства в заданном сегменте глобального рынка.

Таблица 3. Факторы, сдерживающие инвестиционную деятельность предприятий малого бизнеса в 2017 и 2018 г.г.,\%

\begin{tabular}{|l|c|c|}
\hline & 2017 & 2018 \\
\hline 1. Недостаточный спрос на продукцию & 23 & 27 \\
\hline $\begin{array}{l}\text { 2. Несовершенная нормативно-правовая база, регулирующая инвестицион- } \\
\text { ные процессы }\end{array}$ & 21 & 35 \\
\hline $\begin{array}{l}\text { 3. Сложный механизм получения кредитов для реализации инвестиционных } \\
\text { проектов }\end{array}$ & 35 & 48 \\
\hline 4. Инвестиционные риски & 31 & 47 \\
\hline 5. Высокий процент коммерческого кредита & 41 & 54 \\
\hline 6. Высокий уровень инфляции в стране & 38 & 58 \\
\hline 7. Недостаток собственных финансовых средств & 44 & 49 \\
\hline 8. Неопределенность экономической ситуации в стране & 42 & 61 \\
\hline
\end{tabular}

Составлено авторами по данным Федеральной службы государственной статистики 


\section{Библиографический список}

1. Поддержка бизнеса в период распространения коронавируса: что сделано Информационный ресурс http:// duma.gov.ru/news/48315/ Дата обращения 25.10.2020[1]

2. Совещание о санитарно-эпидемиологической обстановке. Информационный pecypc http://kremlin.ru/ events/president/news/63340 [2]. Дата обращения 19.10.2020

3. «Официальная информация о короновирусе в России» Информационный pecypc https:/ xn-80aesfpebagmfblc0a.xn - p1ai/what-to-do/business/ Дата обращения 28.10.2020.

4. О. Кайтялиди «Как трансформировать бизнес-модели: алгоритмы, которые работают», Billionaires Business School. 09.03.2020. Интернет -ресурс https://billionaireschool.ru/kak-transformirovat-biznes-modelialgoritmy-kotorye-rabotajut/ (Дата обращения 17.02.2021)

5. Талеб Н. Н. Черный лебедь. Под знаком неопределенности. М.: КоЛибри, Азбука-Аттикус, 2012.

6. Талеб Н. Н. Антихрупкость. Как извлечь выгоду из хаоса. М.: КоЛибри, Азбука - Аттикус, 2017.

7. Жабин А.П, Волкдавова Е.В., Кандрашина Е.А. Управление предпринимательскими рисками, или “черный лебедь» Covid-19 как тест на антихрупкость. Вестник Самарского государственного экономического университета. 2020. № 3 (185). С. 38-45.

8. Тамбовцев В.Л. Стратегическая теория фирмы: состояние и возможное развитие // Российский журнал менеджмента. 2010. Т. 8. № 1. C. 5-40. URL: https://elibrary.ru/item. asp?id=13571166

9. Малое и среднее предпринимательство в России. 2019: Стат.сб./ М 19 Росстат.- М., 2019._ С.42.

10. Линц К. Радикальное изменение бизнес-модели. Адаптация и выживание в конкурентной среде / К. Линц, Г. Мюллер-Стивенс, А. Циммерман. - М.: Альпина Паблишер, 2019. - 311 с

11. Гассман О. Бизнес-модели. 55 лучших шаблонов / О. Гассман, К. Фрагкенбергер, М.Шик.- М.: Альпина Паблишер, 2019. - 432 с 